\title{
Analysis of Radar Cross Section Reduction of Fighter Aircraft by Means of Computer Simulation
}

\author{
Luiz Alberto de Andrade ${ }^{1}$, Luan Silva Carvalho dos Santos ${ }^{1}$, Adriana Medeiros Gama ${ }^{1}$
}

\begin{abstract}
This paper presents a preliminary study of the Radar Cross Section (RCS) reduction on the fighter aircraft. First, it was studied the RCS of the aircraft from computational simulations based on prior knowledge of vulnerable areas of this aircraft to radar threats. Subsequently, the possible applications of Radar Absorbing Materials (RAM) on the surface of the aircraft were evaluated, in order to reduce its RCS. The absorber material used in the simulations was denominated FC70, which has good attenuation in the range of 10 to $12 \mathrm{GHz}$. The study of this reduction was accomplished by applying RAM in four different scenarios at the frequency of $11.1 \mathrm{GHz}$, where the material is more sensitive. The RCS simulations of the fighter aircraft and its RCS reduction by RAM application were carried out with the support of the software "Computer Simulation Technology" (CST), version 2012. Such technology makes it possible to simulate the application with an absorber material layer on the surface of the aircraft. For the study of the RCS reduction on the fighter aircraft, it was first necessary to develop a detailed $3 \mathrm{D}$ model of the fighter aircraft, and it was developed with the software "Computer Aided Three-Dimensional Interactive Application" (CATIA). In conclusion, it is impossible to make much progress attempting to retrofit stealth onto a conventional aircraft because if the shape is wrong, no amount of absorbing material treatments will reduce the RCS.
\end{abstract}

KEYWORDS: Radar cross section, Radar absorber material, Computational simulation, Radar cross section reduction.

\section{INTRODUCTION}

The goal to reduce a military aircraft's RCS is directly related to the distance at which it can be detected by hostile radars. The radar equation given below (Eq.1) provides a quantitative way to analyze the impact of a target's RCS reduction in its distance for monostatic radars (Knott et al., 1993):

$\left.R_{\max }=\left[\left(P_{\mathrm{t}} G^{2} \lambda^{2} \sigma\right) /(4 \pi)^{3} P_{\min } L\right)\right]^{1 / 4}$

Where: $R_{\max }$ is the maximum range of the radar detection, $P_{\mathrm{t}}$ is the radar antenna's transmission power, $P_{\min }$ is the minimum power detected by the radar, $G=G_{\mathrm{r}}=G_{\mathrm{t}}$ is the radar gain, $L$ are the losses associated to the radar electronics and the environment, and $\sigma$ is the RCS (Gama and Rezende, 2010; CST, 2012).

When analyzing Eq.1, it is revealed that among the variables of the radar equation, only one possible control by the target aircraft is its RCS, all others are inherent to either the hostile radar system or the environment. Therefore, from the point of view of the aircraft, the radar parameters and the environment can be considered as a constant of the detection system. An examination of Eq.1 shows that the RCS of a target should be decreased by sixteen times, so that the maximum detection distance $R$ falls by its half.

\section{METHODOLOGY}

The computational resource used in this study was the CATIA V5 software, responsible for the development of 3-D models of the aircraft which shall have the reduction of its 
RCS studied. In order to study the electromagnetic scattering, the package A-Solver (asymptotic solver) of the Computer Simulation Technology software - CST 2012 version - was used (Gama and Rezende, 2005). In the interest of studying the RCS reduction, the RAM FC70 was inserted on the library of the CST (Gama and Rezende, 2010; Gama and Rezende, 2005; Gama et al., 2011),which simulated its application in parts of the surface of the aircraft, called Scenarios 1, 2, 3 and 4 .

In order to facilitate the RCS's simulations on the F-5 and to modify the aircraft, because it is still in operation, some of its characteristics were modified (CST, 2013; CATIA, 2010; EMBRAER, 2005). The simplifications were: the setting of a metallic canopy, the removal of external antennas, the withdrawal of navigation and training lights, as well as the removal of "probe" for refueling during flight, weapons and engines. Figure 1 shows, in detail, a three dimensional model

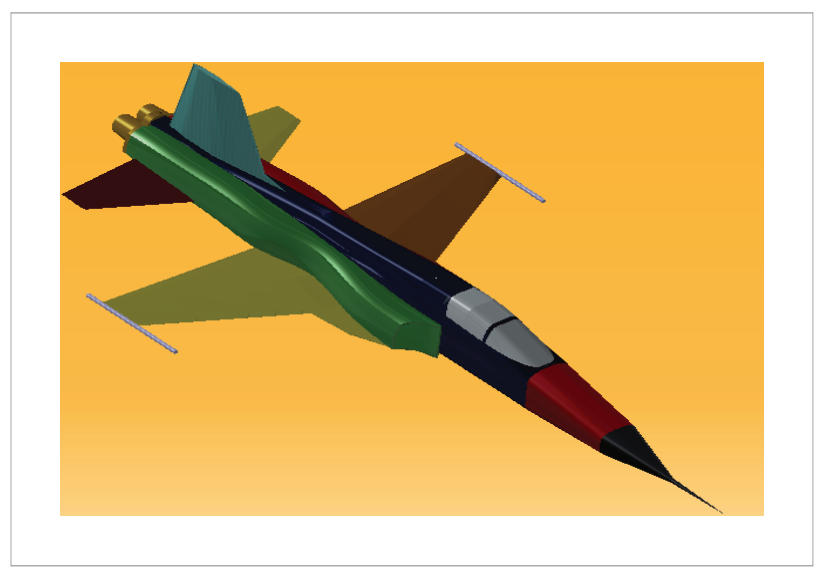

Figure 1. 3-D perspective model of the fighter aircraft developed with the CATIA software.

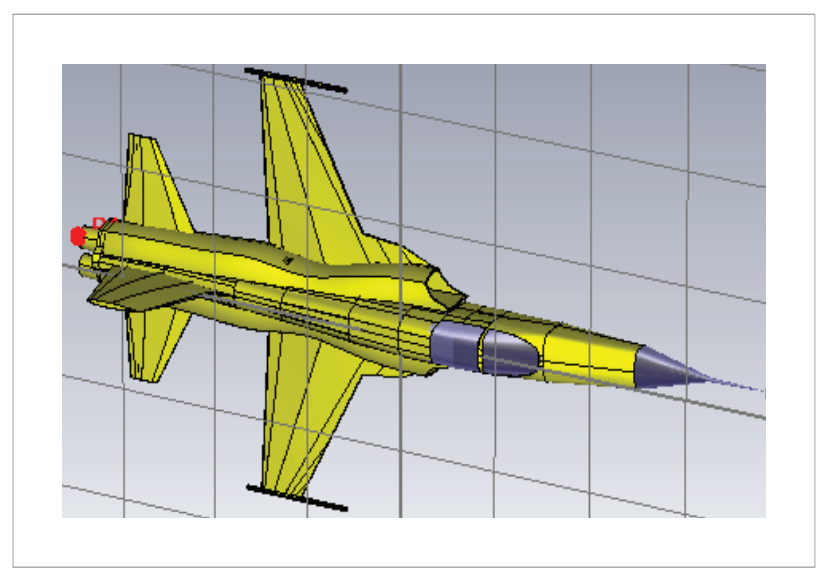

Figure 2. Aircraft fighter aircraft partially coated with RAM, Scenario 1. split to enable the necessary RAM application according to Scenarios 1, 2, 3 and 4 (Alves et al., 2006).

In Scenario 1, an almost covered aircraft is presented. The RAM were not applied on the canopy because it would compromise the pilot's vision nor on the Radome's surface because it could attenuate the signal emitted and received by its own radar.

In Scenario 2, in addition to the surfaces uncovered in Scenario 1, the turbine palettes and exhaust were not coated either.

In Scenario 3, in addition to the parts not covered in Scenario 2, the air inlet of the aircraft was not coated, and in Scenario 4, only the horizontal and vertical stabilizers were coated, in addition to the uncoated parts in Scenario 3, the wings, fuselage's parts and aircraft's rear.

Figures 2, 3, 4 and 5 illustrate, respectively, Scenarios 1, 2, 3 and 4 , where the fighter aircraft is partially coated with RAM, noticing that coated surfaces are yellow and uncoated surfaces are grey.

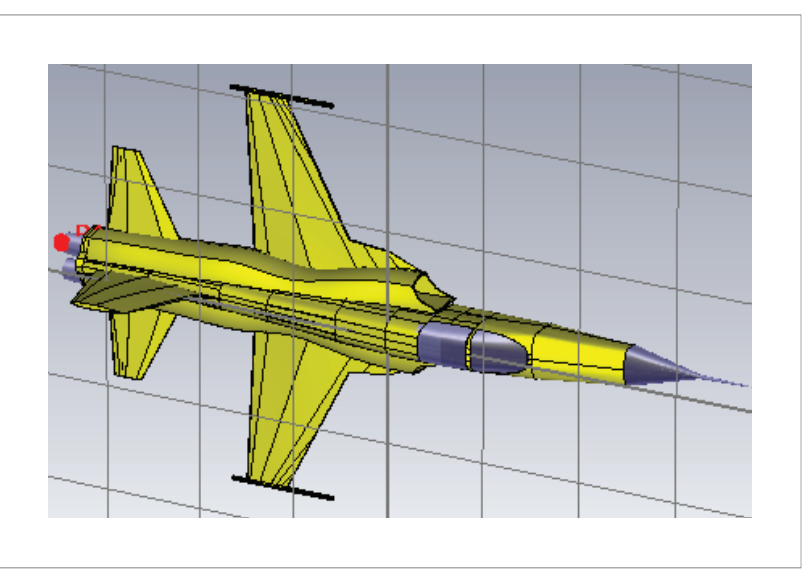

Figure 3. Fighter aircraft partially coated with RAM, Scenario 2.

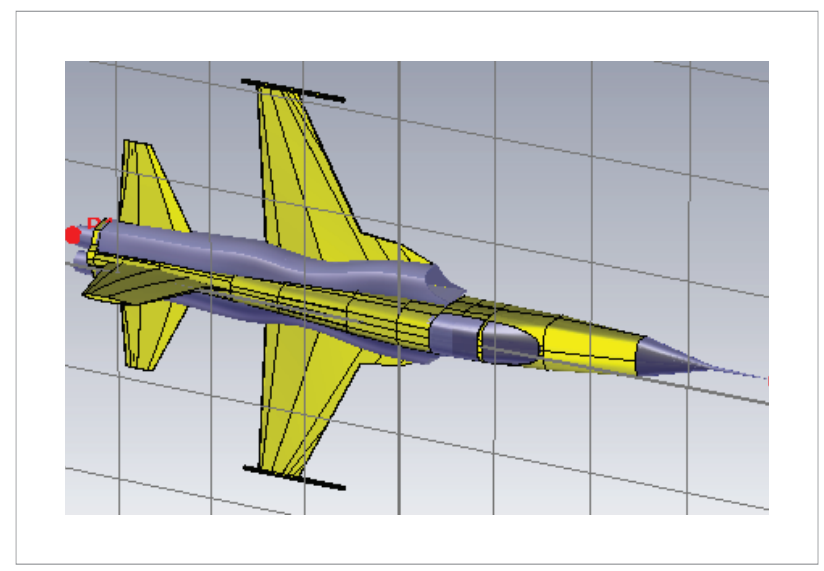

Figure 4. Fighter aircraft partially coated with RAM, Scenario 3. 


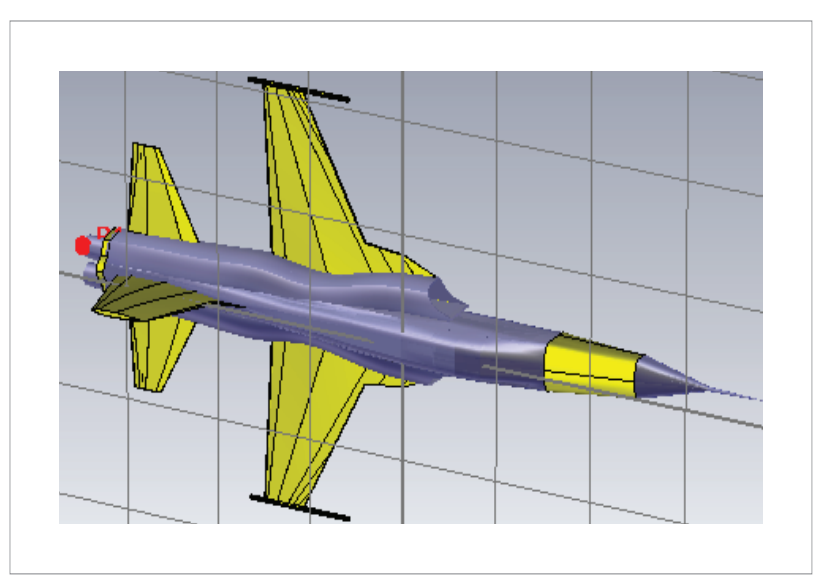

Figure 5. Fighter aircraft partially coated with RAM, Scenario 4.

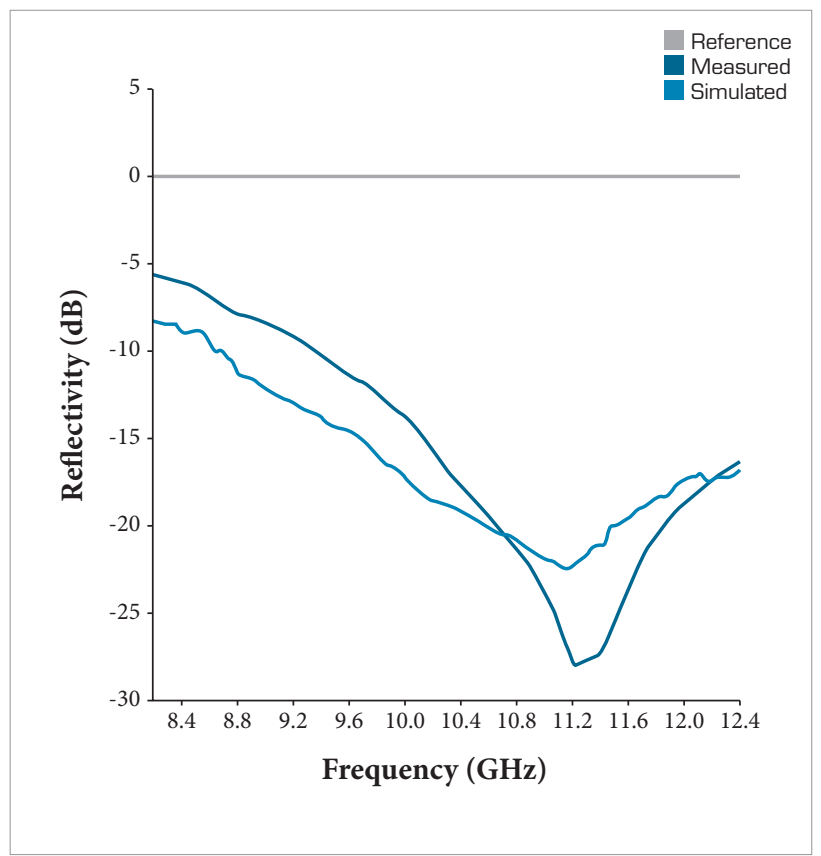

Figure 6. The reflectivity curve of the RAM FC70 used for RCS reduction.

Table 1. Comparison between the measured and the simulated reflectivity of the RAM FC70.

\begin{tabular}{|c|c|c|}
\hline \multirow{2}{*}{ Frequency $[\mathrm{GHz}]$} & \multicolumn{2}{|c|}{ Reflectivity } \\
\cline { 2 - 3 } & Measured & Theoretical \\
\hline 8.2 & -5.48852 & -8.28 \\
\hline 11.1 & -26.17 & -22.60 \\
\hline 11.2 & -28.06 & -22.06 \\
\hline 12.4 & -16.5625 & -16.96 \\
\hline
\end{tabular}

Figure 6 and Table 1 show the comparison between the reflectivity measured and simulated with the CST software, and the RAM FC70 used in this study of RCS reduction.

The difference between the theoretical and the measured curve is due to inhomogeneity of the material and the variation in the thickness of the sample.

\section{RESULTS}

The preliminary study of RCS reduction on the fighter aircraft, by managed application of RAM, was performed at the frequency of $11.1 \mathrm{GHz}$, with aspect angles ranging from $0^{\circ}$ to $360^{\circ}$ with increments of $1^{\circ}$. All simulations were performed in the same frequency because RAM is more sensitive.

All RCS simulations were made using the package Asymptotic Solver (A-Solver), with a Gaussian excitation, vertical polarization and Triangular Mesh. Around 2,000,000 elements were generated. Figure 7 shows a comparison between RCS of the fighter aircraft at the frequency of 11.1 $\mathrm{GHz}$, partially coated and uncoated with RAM, as shown in Fig. 2 (Scenario 1).

Figure 8 shows a comparison between RCS of the fighter aircraft at $11.1 \mathrm{GHz}$, partially coated and uncoated with RAM, as shown in Fig. 3 (Scenario 2).

Figure 9 shows a comparison between RCS of the fighter aircraft at $11.1 \mathrm{GHz}$, partially coated and uncoated with RAM, as shown in Fig. 4 (Scenario 3).

Figure 10 shows a comparison between RCS of the fighter aircraft at frequency $11.1 \mathrm{GHz}$, partially coated and uncoated with RAM, as shown in Fig. 5 (Scenario 4).

Table 2 shows a comparison between peak values of RCS at $11.1 \mathrm{GHz}$ and RCS in the frontal, lateral, and rear portions of the fighter aircraft.

Tables 3 and 4 show values of RCS at $11.1 \mathrm{GHz}$ in units of decibels square meter $(\mathrm{dBsm})$ and square meter $\left(\mathrm{m}^{2}\right)$, respectively. The average was taken in intervals of $10^{\circ}$ for RCS in the frontal, lateral, and rear portions of the fighter aircraft.

Typical radars detect aircrafts with a frontal RCS of $5 \mathrm{~m}^{2}$ within $165 \mathrm{~km}$ of distance. Using the Eq. 1 and the results from Table 4, the reach of radars after applications of RAM, according to the scenarios presented, was estimated. Table 5 shows the reach of radars before and after applications of RAM. 


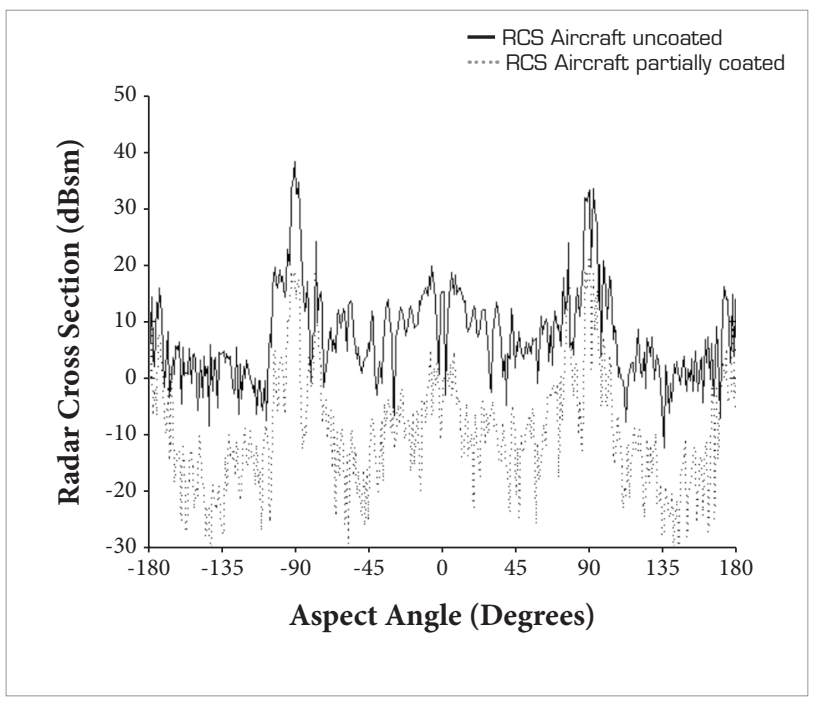

Figure 7. Scenario 1 - Comparison between the RCS of the fighter aircraft at $11.1 \mathrm{GHz}$, partially coated and uncoated with RAM.

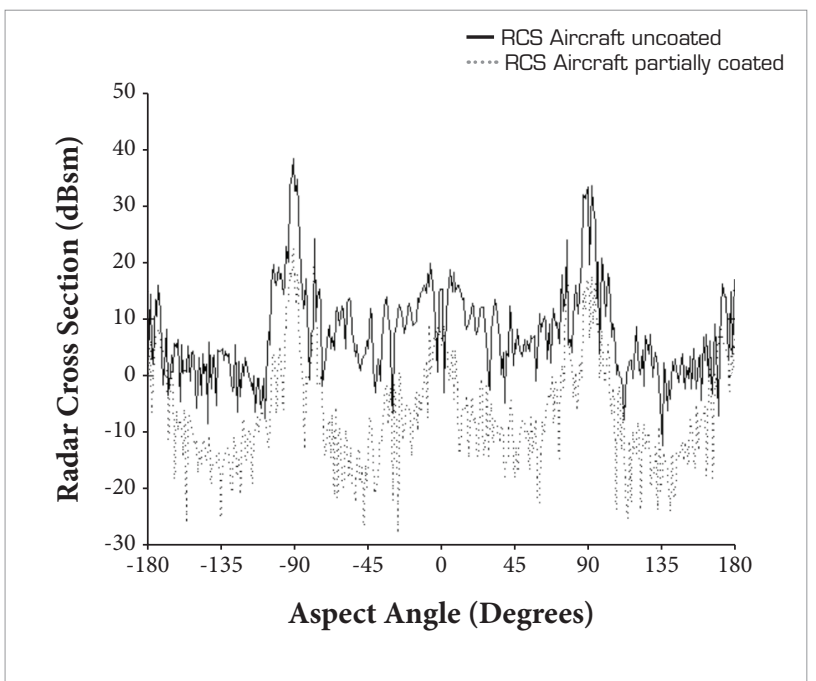

Figure 8. Scenario 2 - Comparison between the RCS of fighter aircraft at $11.1 \mathrm{GHz}$, partially coated and uncoated with RAM.

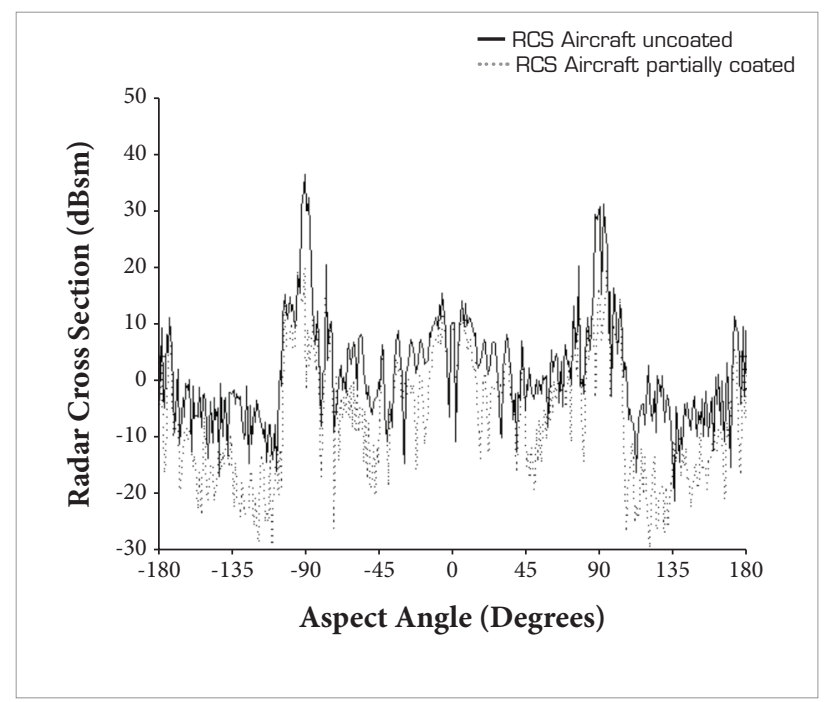

Figure 9. Scenario 3 - Comparison between the RCS of the fighter aircraft at $11.1 \mathrm{GHz}$, partially coated and uncoated with RAM.

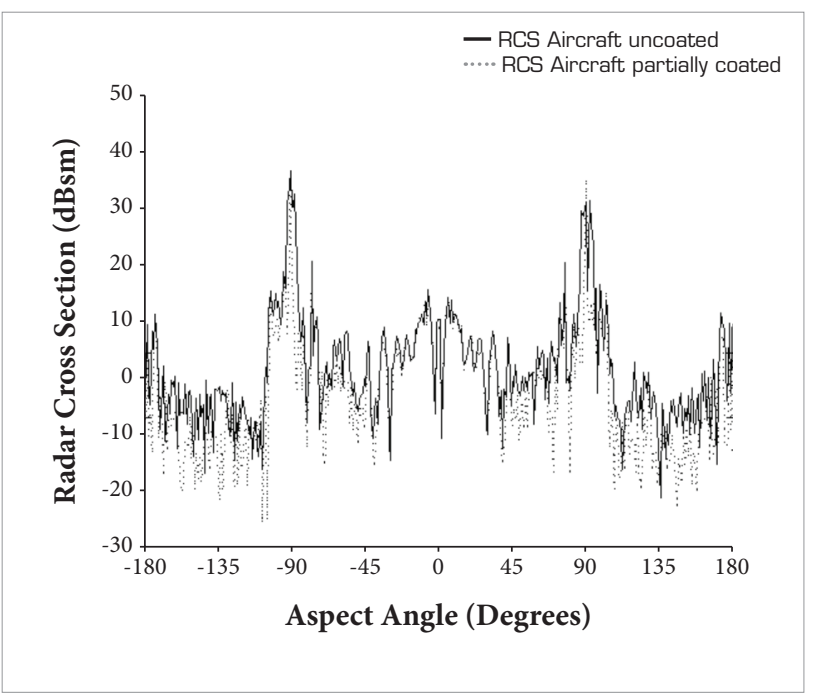

Figure 10. Scenario 4 - Comparison between the RCS of the fighter aircraft at $11.1 \mathrm{GHz}$, partially coated and uncoated with RAM.

Table 2. Comparison between the RCS of the fighter aircraft at $11.1 \mathrm{GHz}$ frequency, uncoated and partially coated with RAM FC70.

\begin{tabular}{|c|c|c|c|c|c|c|}
\hline & & \multicolumn{5}{|c|}{ Peak RCS in dBsm } \\
\hline \multirow{2}{*}{\multicolumn{2}{|c|}{ Incidence }} & \multirow{2}{*}{ Uncoated } & \multicolumn{4}{|c|}{ Scenarios [Coated with RAM] } \\
\hline & & & 1 & 2 & 3 & 4 \\
\hline Frontal & $0^{\circ}$ & 15.20 & -5.42 & 7.79 & 13.6 & 17.2 \\
\hline Lateral & $90^{\circ}$ & 33.10 & 21.40 & 17.00 & 16.6 & 36.7 \\
\hline Rear & $180^{\circ}$ & 30.50 & 5.41 & 11.30 & 15.3 & 16.2 \\
\hline
\end{tabular}


Table 3. Comparison between the fighter aircraft RCS average at $11.1 \mathrm{GHz}$ frequency uncoated and partially coated with RAM FC70.

\begin{tabular}{|c|c|c|c|c|c|c|}
\hline \multirow{3}{*}{\multicolumn{2}{|c|}{ Incidence }} & \multicolumn{5}{|c|}{ Average RCS in dBsm } \\
\hline & & \multirow{2}{*}{ Uncoated } & \multicolumn{4}{|c|}{ Scenarios [Coated with RAM] } \\
\hline & & & 1 & 2 & 3 & 4 \\
\hline Frontal & $-5^{\circ}$ to $5^{\circ}$ & 10.20 & -1.11 & 5.51 & 10.80 & 10.9 \\
\hline Lateral & $85^{\circ}$ to $95^{\circ}$ & 26.30 & 9.70 & 11.00 & 16.00 & 17.50 \\
\hline Rear & $-175^{\circ}$ to $175^{\circ}$ & 10.50 & 0.16 & 2.75 & 3.03 & 3.93 \\
\hline
\end{tabular}

Table 4. Comparison between the fighter aircraft RCS average at $11.1 \mathrm{GHz}$ frequency uncoated and partially coated with RAM FC70.

\begin{tabular}{|c|c|c|c|c|c|c|}
\hline \multirow{3}{*}{\multicolumn{2}{|c|}{ Incidence }} & \multicolumn{5}{|c|}{ Average RCS in $\mathrm{m}^{2}$} \\
\hline & & \multirow{2}{*}{ Uncoated } & \multicolumn{4}{|c|}{ Scenarios [Coated with RAM] } \\
\hline & & & 1 & 2 & 3 & 4 \\
\hline Frontal & $-5^{\circ}$ to $5^{\circ}$ & 10.47 & 0.77 & 3.55 & 12.02 & 12.30 \\
\hline Lateral & $85^{\circ}$ to $95^{\circ}$ & 426.58 & 9.33 & 12.59 & 39.81 & 56.23 \\
\hline Rear & $-175^{\circ}$ to $175^{\circ}$ & 11.22 & 1.04 & 1.88 & 2.00 & 2.47 \\
\hline
\end{tabular}

Table 5. Comparison between the detection distance of the fighter aircraft in the frequency of $11.1 \mathrm{GHz}$ to a typical radar using the average RCS, uncoated and coated with RAM FC7O.

\begin{tabular}{|c|c|c|c|c|c|c|}
\hline \multirow{3}{*}{\multicolumn{2}{|c|}{ Incidence }} & \multicolumn{5}{|c|}{$\mathbf{R}_{\max }$ in $\mathbf{k m}$} \\
\hline & & \multirow{2}{*}{ Uncoated } & \multicolumn{4}{|c|}{ Scenarios [Coated with RAM] } \\
\hline & & & 1 & 2 & 3 & 4 \\
\hline Frontal & $-5^{\circ}$ to $5^{\circ}$ & 222.5 & 116.0 & 169.8 & 230.3 & 231.7 \\
\hline Lateral & $85^{\circ}$ to $95^{\circ}$ & 562.2 & 216.2 & 233.0 & 310.7 & 338.8 \\
\hline Rear & $-175^{\circ}$ to $175^{\circ}$ & 226.4 & 124.8 & 144.8 & 147.1 & 155.1 \\
\hline
\end{tabular}

After the application of RAM with a theoretical attenuation of $22.6 \mathrm{~dB}$ at $11.1 \mathrm{GHz}$, for Scenario 1, the average of frontal RCS presented around $10 \mathrm{~dB}$ of attenuation. While the maximum range of the radar detection fell from $222 \mathrm{~km}$ to $116 \mathrm{~km}$, i.e. the aircraft fighter could get $48 \%$ closer to the target before executing the mission. For Scenario 2, whose differences are only changing by the exhaust turbine and the application of RAM for metal, the average of frontal RCS presented around $7 \mathrm{~dB}$ of attenuation. While radar reach fell from $222 \mathrm{~km}$ to $169.8 \mathrm{~km}$, i.e. the aircraft fighter could get $25 \%$ closer to the target before executing the mission. For Scenarios 3 and 4, the application of RAM proved to be inefficient for frontal RCS reduction.

\section{CONCLUSIONS}

Nowadays, for an aircraft to be considered stealth, it shouldn't be detected in less than $20 \mathrm{~km}$ of distance. However, this value can vary considerably depending on the technological advancement of radar detection systems and stealth technology. It is impossible to make much progress attempting to retrofit stealth onto a conventional aircraft because if the shape is wrong, no amount of material absorber treatments will reduce the RCS. Consideration must be given to any part of an aircraft to which a radar wave can reach to, in order to develop a low observable aircraft. On the other hand, the first critical factor to consider in the design process is the shape of the aircraft. This element has been designed into the aircraft from the beginning. 


\section{REFERENCES}

Alves, M.A., Andrade, L.A. and Rezende, M.C., 2006, "Influência da discretização de modelos em simulações de seção reta radar" In: Anais do VIII Simpósio de Guerra Eletrônica, São José dos Campos, Br, Vol. 1, pp. 1-4.

CATIA, 2010, Manual do Usuário, Available from: www.catia.com. Acessed on: 20 May 2013.

CST, 2013, Manual do Usuário CST Studio Suite versão 2012. Available from: www.cst.com. Acessed on: 20 May 2013.

EMBRAER. T.O. 1F - 5EM - 1, 2005, São José dos Campos, BR.

Gama, A.M. and Rezende, M.C., 2005, "The relationship between Mn-Zn ferrites with different iron ion contents and the absorption energy in X-band", Proceedings of the IEEE, Vol. 1, pp. 322-325. doi: 10.1109/IMOC.2205.1580009.
Gama, A.M. and Rezende, M.C., 2010, “Complex permeability and permittivity variation of carbonyl iron rubber in the frequency range of 2 to $18 \mathrm{GHz}$, Journal of Aerospace Technology and Management, Vol. 2, No. 1, pp.59-62. doi: 10.5028/jatm.2010.02015962.

Gama, A.M., Rezende, M.C. and Dantas, C.C., 2011, "Dependence of microwave absorption properties on ferrite volume fraction in MnZn ferrite/rubber radar absorbing materials", Journal of Magnetism and Magnetic Materials, Vol. 323, No. 2, pp. 2782-2785. doi: 10.1016/j.jmmm.2011.05.052.

Knott, E.F., Schaeffer, J.F. and Tuley, M.T., 1993, "Radar Cross Section", 2nd edition, Artech House Inc., USA, Chen, W.K., 1993, "Linear Networks and Systems", Book style, Wadsworth, Belmont, US, pp. 123-135. 